\title{
Effect of leucovorin on the antitumor efficacy of the 5-FU prodrug, tegafur-uracil, in human colorectal cancer xenografts with various expression levels of thymidylate synthase
}

\author{
HIROAKI TSUJIMOTO, SAYAKA TSUKIOKA, SATORU ONO, ETSUKO SAKAMOTO, \\ KAZUKI SAKAMOTO, KOHJI TSUTA, FUMIO NAKAGAWA, HITOSHI SAITO, \\ JUNJI UCHIDA, MAMORU KINIWA and MASAKAZU FUKUSHIMA
}

Tokushima Research Center, Taiho Pharmaceutical Co., Ltd., Tokushima 771-0194, Japan

Received July 8, 2010; Accepted August 25, 2010

DOI: $10.3892 / \mathrm{ol} .2010 .172$

\begin{abstract}
The combination of oral tegafur-uracil (UFT) with leucovorin (LV) is used to treat patients with stage II to III colon cancer based on the results of postoperative randomized studies in which UFT/LV treatment showed an equivalent efficacy to intravenous 5-FU plus LV therapy. However, whether the addition of LV to UFT can elevate the antitumor activity of UFT in colorectal tumors with high expression levels of thymidylate synthase (TS), which affects 5-FU efficacy, remains to be clarified. This study investigated the effect of LV on the antitumor activity of UFT and/or 5-FU prodrugs in low folate diet-fed nude mice using human colorectal cancer xenografts with various expression levels of TS. The addition of LV to UFT resulted in a 55-79\% inhibition of tumor growth among 11 types of colorectal tumor xenograft, whereas UFT alone showed 23-67\% antitumor activity. Although there was an inverse relationship between the antitumor effect of UFT alone and UFT plus LV and tumoral TS activity, UFT plus LV appeared to have a more potent antitumor effect than UFT alone on colorectal tumors such as $\mathrm{Co}-3$ and $\mathrm{KM} 12 \mathrm{C} / 5-\mathrm{FU}$ with high expression levels of TS. This finding was confirmed by the significant positive correlation between the relative inhibition ratio of UFT/LV to UFT alone and TS levels in tumors. To investigate the reason for the higher efficacy of UFT/LV on colorectal cancer xenografts with high TS activity, intratumoral levels of reduced folates and a ternary complex of TS after oral UFT with or without LV were measured using Co-3 xenografts. Elevated levels of reduced folates and an increased ternary complex of TS in LV-treated tumors were noted. Our results indicate that a combined therapy of UFT with LV may contribute to the treatment of colorectal cancer
\end{abstract}

Correspondence to: Dr Hiroaki Tsujimoto, Tokushima Research Center, Taiho Pharmaceutical Co., Ltd., 224-2 Hiraishi-ebisuno Kawauchi-cho, Tokushima 771-0194, Japan

E-mail: h-tsujimoto@taiho.co.jp

Key words: tegafur-uracil, leucovorin, capecitabine, thymidylate synthase, reduced folate patients with low and high expression levels of tumoral TS by increased formation of the ternary complex of TS leading to potentiated antitumor efficacy of UFT.

\section{Introduction}

5-Fluorouracil (5-FU) plus leucovorin (LV)-based chemotherapy is used worldwide to treat patients with colorectal cancer (CRC) in the advanced/metastatic or adjuvant setting. At present, clinically based on a 5-FU/LV regimen, the addition of oxaliplatin (oxaliplatin-based therapy) or irinotecan (CPT-11-based therapy) to 5-FU/LV has been shown to significantly improve the clinical responses and survival of CRC patients. Various combination regimens such as FLOX (1), FOLFOX 4 (2), mFOLFOX 6 (3), FOLFOX 7 (4) and FOLFIRI (3) are now available for the treatment of patients. More recently, the molecular-targeted drug bevacizumab, in combination with oxaliplatin-based and/or CPT-based regimens, has been shown to prolong the survival time of CRC patients. Regarding the use of oral fluoropyrimidines instead of intravenous 5-FU, UFT combined with LV and capecitabine have been shown to have equivalent efficacy to 5-FU/LV for the treatment of CRC patients, as noted in tegafur-uracil (UFT)/LV vs. 5-FU/LV (5), NSABP C-06 (6) and X-ACT (7) trials.

UFT is an orally active combination of tegafur (a prodrug of 5-FU) and uracil in a 1:4 molar ratio. FT is mainly metabolized to 5-FU by cytochrome P-450 in the liver, whereas uracil is a biochemical modulator of 5-FU degradation catalyzed by dihydropyrimidine dehydrogenase (DPD) and competes with 5-FU for the enzyme, resulting in significantly high and prolonged plasma 5-FU levels. In tumor cells, 5-FU is metabolized to 5-fluorouridine 5'-monophosphate (FUMP), mainly by uridine monophosphate synthetase, to yield the active form, 5-fluoro-2'-deoxyuridine 5'-monophosphate (FdUMP). FdUMP forms a ternary complex with thymidylate synthase (TS) in the presence of 5,10-methylenetetrahydrofolate $\left(5,10-\mathrm{CH}_{2}-\mathrm{THF}\right)$, a reduced folate, and subsequently inhibits DNA synthesis.

Therefore, TS levels and reduced folate pools in tumors may play a critical role in determining the antitumor efficacy of 5-FU. In this respect, Spears et al reported that an innate 
resistance to 5-FU in $\mathrm{CRC}$ patients receiving 5-FU was partially dependent on higher TS levels and reduced folate pools (8). Furthermore, a number of studies have suggested that the expression levels of TS mRNA and/or TS proteins in primary colorectal tumors predict the clinical outcomes (response rates or survival) of CRC patients receiving 5-FUbased chemotherapy.

$\mathrm{LV}$, as a potentiator of 5-FU efficacy, is metabolized to $5,10-\mathrm{CH}_{2}-\mathrm{THF}$ via $5-\mathrm{CH}_{3}-\mathrm{THF}$ in tumor cells. Since the antitumor effect of 5-FU is enhanced in the presence of abundant $5,10-\mathrm{CH}_{2}-\mathrm{THF}$ as a result of a delay in the dissociation of TS from the ternary complex (9), concomitant use of LV is considered useful when a low antitumor sensitivity of 5-FU proceeds from high TS levels in tumors.

This study was performed to clarify the relationship between TS activity in tumors and the antitumor effects of UFT or UFT/LV in colorectal cancer xenografts with various TS expression levels, and to elucidate the effect of LV in the consequent low effectiveness of 5-FU.

\section{Materials and methods}

Chemicals. UFT and LV were obtained from Taiho Pharmaceutical Co., Ltd. (Tokyo, Japan). Capecitabine was purchased from KNC Laboratories Co., Ltd. (Hyogo, Japan). Hydroxypropylmethylcellulose was purchased from Shin-Etsu Chemical Co., Ltd. (Tokyo, Japan). [6- $\left.{ }^{3} \mathrm{H}\right]$ FdUMP and $\left[\right.$ methyl $\left.-{ }^{3} \mathrm{H}\right]$-thymidine were purchased from Moravek Biochemicals Inc. (Brea, CA, USA). The other chemicals used were commercially available.

Human colon cancer cells. The colorectal cancer cell lines used in this study were obtained from the following sources: Colo 201 and Colo 320DM were from the Health Science Research Resources Bank (Tokyo, Japan); WiDr, Colo 205, HCT-15, DLD-1 and LoVo were from Dainippon Pharma Co., Ltd. (Osaka, Japan); Col-1 and Co-3 were from the Central Institute for Experimental Animals (Kanagawa, Japan); KM12C was kindly provided by Dr K. Morikawa (National Cancer Center, Tokyo, Japan); and KM12C/5-FU was from Taiho Pharmaceutical Co., Ltd. The passage of each tumor cell line was maintained by subcutaneous implantation into male BALB/cA Jcl $n u / n u \cdot$ mice.

Animals. Male BALB/c-nu/nu mice were procured from CLEA Japan, Inc. The animals were given unrestricted access to radioactively $(30 \mathrm{kGy})$ sterilized solid feed without folic acid supplementation (Oriental Yeast Co., Ltd., Japan) from the date of delivery until the final day of the experiment $(10,11)$.

Human cancer xenograft models. Tumors subcutaneously implanted and passaged in nude mice were extracted to prepare tumor fragments of $\sim 2 \mathrm{~mm}^{2}$, which were then subcutaneously implanted into the right side of the back of other nude mice using a graft needle. To assess the antitumor effect, the long and short diameters of the tumors were determined, and the animals were assigned to groups in order that the tumor volume (TV), calculated using the formula i), was uniform among the groups (day 0). The drug was orally administered for 14 consecutive days from the day after grouping, and the relative tumor volume [RTV, determined using the formula ii)] and inhibition ratio of tumor growth [IR, \%, determined using the formula iii)] on day 15 were calculated.

i) TV $\left(\mathrm{mm}^{3}\right)=$ length $(\mathrm{mm}) \mathrm{x}$ width $(\mathrm{mm}) \mathrm{x}$ width $(\mathrm{mm}) \times 0.5$

ii) $\mathrm{RTV}=(\mathrm{TV}$ on day 15$) /(\mathrm{TV}$ on day 0$)$

iii) IR $(\%)=[1-($ mean RTV in drug group $) /($ mean RTV in vehicle group)] x 100

The tolerated dose of UFT was considered to be $20 \mathrm{mg} / \mathrm{kg} /$ day (12), as cachexia occurs in mice implanted with human colon tumors, whereas the dose of concomitant LV was set at $10 \mathrm{mg} / \mathrm{kg} /$ day. Similarly, the dose of capecitabine was $450 \mathrm{mg} /$ $\mathrm{kg} /$ day (13). As an index of general toxicity, the animals were weighed over time. However, since a decrease in mean bodyweight change (BWC) occurred in the control group due to cachexia in the colorectal cancer xenograft model, we used the $\triangle \mathrm{BWC}$ value obtained by subtracting the mean BWC in the control group from that in each drug group as an index for toxicity assessment.

Tumor growth delay. To assess the antitumor effect of UFT monotherapy and that of UFT/LV concomitant therapy in a xenograft model in which Co-3 tumor cells were implanted, the RTV was calculated until day 29 , i.e., beyond completion of the 14-day consecutive oral administration, to assess the delay in tumor growth. Time in the experimental period was plotted on the X-axis, whereas the mean RTV values in the control, LV monotherapy, UFT monotherapy and UFT/LV concomitant therapy groups were plotted on the Y-axis. Each linear function was obtained from the values of the days when the mean RTV of each group was lower or higher than 10, and the number of days on which RTV corresponded to 10 was calculated. The value obtained by subtracting the value in the control group from the RTV10 value in each drug group was used as the period of growth delay.

TS binding assay. Tumor tissues were homogenized in $10 \mathrm{mM}$ Tris buffer (pH 7.4) containing $1 \mathrm{mM}$ EDTA and $0.5 \mathrm{mM}$ DTT. After centrifugation at $105,000 \mathrm{x} \mathrm{g}$ for $60 \mathrm{~min}$, the supernatants were collected. An aliquot of the supernatant was used to determine the soluble protein using the Bradford method (14). TS activity was determined as the number of $\left[6-{ }^{3} \mathrm{H}\right]$ FdUMP binding sites in the supernatant of homogenates as described by Spears et al (15). The supernatant was incubated with [6- $\left.{ }^{3} \mathrm{H}\right] \mathrm{FdUMP}$ in the presence of excess $\mathrm{CH}_{2} \mathrm{FH}_{4}$ for $20 \mathrm{~min}$ at $30^{\circ} \mathrm{C}$, and the radioactivity in the acid-insoluble fraction was measured using a liquid scintillation counter.

TP assay. The thymidine phosphorylase (TP) assay was performed using the supernatant prepared in the TS assay. The reaction mixture $(125 \mu \mathrm{l})$ for the assay of enzyme activity contained $100 \mathrm{mM}$ potassium phosphate ( $\mathrm{pH} 7.4), 10 \mu \mathrm{M}$ BAU, $400 \mathrm{nM}$ [methyl- $\left.{ }^{3} \mathrm{H}\right]$-thymidine, and the supernatant of homogenates. The reaction was carried out at $37^{\circ} \mathrm{C}$ for $10 \mathrm{~min}$ and then terminated by the addition of $375 \mu \mathrm{l}$ of methanol. After removal of the precipitate using filtration, the reaction mixture was dried and dissolved in distilled water $(100 \mu \mathrm{l})$. The solution 
Table I. The antitumor activity of fluoropyrimidines against human colon cancer xenografts in mice.

\begin{tabular}{|c|c|c|c|c|}
\hline \multirow[b]{2}{*}{ Cell line } & \multicolumn{4}{|c|}{ IR (\%) } \\
\hline & $\begin{array}{c}\text { UFT alone } \\
20 \mathrm{mg} / \mathrm{kg} / \text { day }\end{array}$ & $\begin{array}{c}\text { UFT/LV } \\
20 / 10 \mathrm{mg} / \mathrm{kg} / \text { day }\end{array}$ & & $\begin{array}{l}\text { Capecitabine } \\
450 \mathrm{mg} / \mathrm{kg} / \mathrm{day}\end{array}$ \\
\hline Colo 205 & 66.7 & 73.2 & $\mathrm{~b}$ & 69.4 \\
\hline WiDr & 59.3 & 71.9 & $\mathrm{~b}$ & 48.2 \\
\hline Colo 201 & 48.8 & 61.5 & $\mathrm{~b}$ & 48.6 \\
\hline KM12C & 54.5 & 78.8 & $\mathrm{~b}$ & 57.8 \\
\hline Col-1 & 49.1 & 68.2 & $\mathrm{~b}$ & 30.3 \\
\hline HCT-15 & 50.5 & 59.8 & $\mathrm{a}$ & 68.4 \\
\hline DLD-1 & 48.8 & 56.2 & n.s. & 28.0 \\
\hline LoVo & 51.5 & 61.0 & $\mathrm{~b}$ & 77.6 \\
\hline Colo 320DM & 52.3 & 60.3 & $\mathrm{a}$ & 35.0 \\
\hline Co-3 & 47.1 & 62.2 & $\mathrm{~b}$ & 33.1 \\
\hline KM12C/FU & 22.8 & 55.1 & $\mathrm{~b}$ & 17.7 \\
\hline
\end{tabular}

The drugs were orally administered once daily for 14 consecutive days. On day 15, the inhibition ratio (IR) of each drug was evaluated. Each value is the mean IR of 6 mice tested. ${ }^{a, b}$ Significantly different from the UFT $20 \mathrm{mg} / \mathrm{kg} /$ day group at $\mathrm{p}<0.05$ and $\mathrm{p}<0.01$ (Student's t-test), respectively; n.s, not significant.

(940 $\mu \mathrm{l})$ was applied to a high-performance liquid chromatography (HPLC) column (TSK-GEL ODS-100V). The solvent system used was: solvent A, water:acetonitrile (95.5:4.5); solvent $\mathrm{B}$, acetonitrile. The elution gradient used was: $0 \% \mathrm{~B}$ for $8.5 \mathrm{~min}, 0-100 \%$ in $0.5 \mathrm{~min}, 100 \% \mathrm{~B}$ for $2.5 \mathrm{~min}, 100-0 \%$ $\mathrm{B}$ in $0.5 \mathrm{~min}$ and $0 \% \mathrm{~B}$ for $12.0 \mathrm{~min}$. The solvent flow rate was $1.0 \mathrm{ml} / \mathrm{min}$. The amount of thymidine converted to thymine was measured using a radio-HPLC detector. TP activity was expressed as pmol of thymine converted $/ \mathrm{mg}$ of protein $/ \mathrm{min}$.

Folate assay. LV $10 \mathrm{mg} / \mathrm{kg}$ was administered to nude mice implanted with Co-3 tumor cells and fed a low folate diet. The tumor tissue was collected after $24 \mathrm{~h}$, frozen in liquid nitrogen immediately and stored at $-80^{\circ} \mathrm{C}$ until the start of the measurement procedure. Reduced folate $\left(5,10-\mathrm{CH}_{2} \mathrm{FH}_{4}+\mathrm{FH}_{4}\right)$ was determined by a modified TS-FdUMP binding assay in which human recombinant TS was added to the reaction system (16).

Immunological detection of thymidylate synthase-FdUMP5,10-methylenetetrahydrofolate ternary complex with anti-human TS polyclonal antibody. The amount of TS ternary complex formed and the amount of free TS in the tumor tissues after drug administration was measured using Western blotting $(17,18)$. UFT $20 \mathrm{mg} / \mathrm{kg}$ alone or UFT $20 \mathrm{mg} / \mathrm{kg}$ combined with $\mathrm{LV} 10 \mathrm{mg} / \mathrm{kg}$ was administered to nude mice implanted with Co-3 tumor cells and fed a low folate diet. The tumor tissue was collected after $24 \mathrm{~h}$, frozen in liquid nitrogen immediately and stored at $-80^{\circ} \mathrm{C}$ until the start of the measurement procedure. The tumor tissue was homogenized and electrophoresed on SDS-polyacrylamide, then transferred to a PVDF membrane. The reaction was performed using anti-human TS rabbit polyclonal antibody (prepared by Taiho Pharmaceutical Co., Ltd.) and HRP-conjugated anti-rabbit
IgG goat polyclonal antibody as the primary and secondary antibodies, respectively. The bands were detected by electrochemiluminescence. The free TS and TS ternary complexes were detected at 36 and $38.5 \mathrm{kDa}$, respectively.

Statistical analysis. To assess the antitumor effect of each drug, the F test, the Student's t-test, the Aspin-Welch t-test and Dunnett's test were used, using SAS Version 8.02, EXSAS Version 7.11 and Microsoft Excel 2000 SR-1 with Windows 2000. For the analysis of antitumor effects and TS and TP activities, Pearson's correlation coefficients were determined using the JMP Version 7 with Windows 2000.

\section{Results}

Antitumor activity of 5-FU prodrugs with or without LV. The antitumor effects of UFT, UFT/LV and capecitabine were assessed for 11 types of colorectal cancer xenograft in mice. Since the tolerated dose of each drug was assumed to be decreased as a result of cachexia (attributable to the implantation of colorectal cancer), the tolerated doses of UFT, UFT/LV and capecitabine were reduced by common ratios of 1.2 to $20,20 / 10$ and $450 \mathrm{mg} / \mathrm{kg} / \mathrm{day}$, respectively, for a 14-day consecutive oral administration. At $24 \mathrm{~h}$ after the final administration (day 15), the tumor diameters were determined, and TV and IR were calculated (Table I). Since the $\triangle B W C$ in each drug group was higher than $-20 \%$ during the experimental period, the toxicity of each drug was within the tolerated range and did not interfere with assessment of the antitumor effect (data not shown). The IR observed with UFT monotherapy was $22.8-66.7 \%$. With an IR of $\geq 50 \%$ considered to be effective, this treatment was effective against $6 / 11$ cell lines (54.5\%). On the other hand, the IR achieved with UFT/ LV concomitant therapy was $55.1-78.8 \%$, with efficacy against 


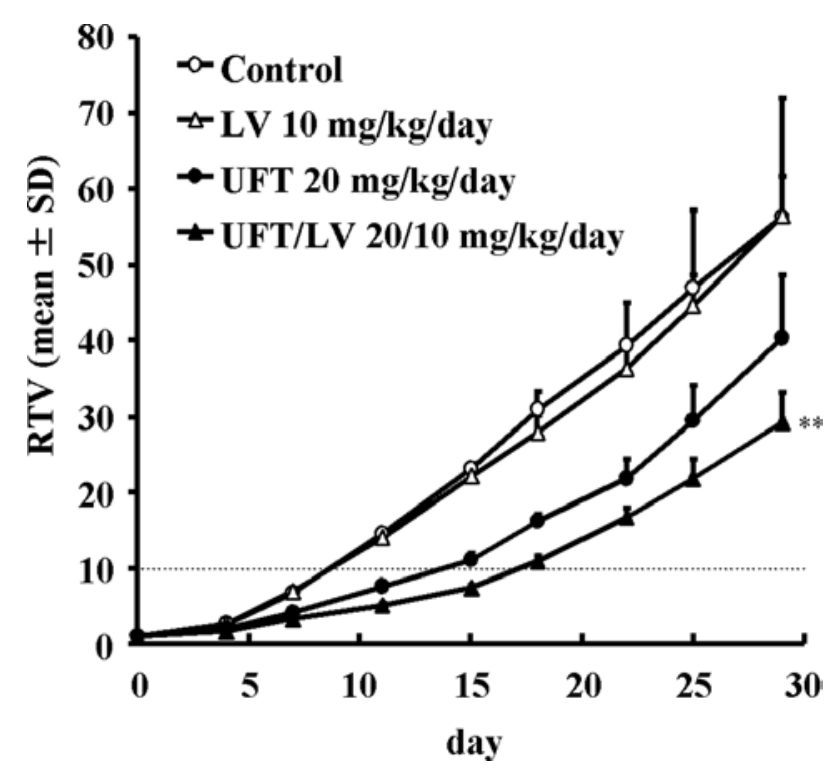

Figure 1. The antitumor effects of UFT and UFT/LV against Co-3 tumor xenografts, as well as the effects of the maximum tested doses of UFT and leucovorin, administered alone or in combination, against Co-3 human colon cancer xenografts are shown. BALB/c-nu/nu mice (n=6/group) were implanted subcutaneously with Co-3 cancer fragments and the treatments were initiated when the mice had tumors of $100-130 \mathrm{~mm}^{3}$. Leucovorin $(10 \mathrm{mg} / \mathrm{kg} / \mathrm{day}, \Delta)$ and UFT $(20 \mathrm{mg} / \mathrm{kg} / \mathrm{day}, \bullet)$ were administered orally on a qd x 14 schedule either alone or in combination ( $\mathbf{\Lambda})$. The changes in mean tumor volume were recorded over time and are expressed as the mean \pm SD. ${ }^{* *}$ Significantly different from the UFT $20 \mathrm{mg} / \mathrm{kg} /$ day group at $\mathrm{p}<0.01$ (Student's t-test). Dotted line, RTV10.

11/11 cell lines (100\%). When LV was used concomitantly, the antitumor effect of UFT was significantly enhanced for 10 of the 11 cell lines (91\%), demonstrating a high antitumor effect. The IR of capecitabine was $17.7-76.6 \%$, with efficacy against $4 / 11$ cell lines (36.4\%). Although the three drugs are oral fluoropyrimidine anticancer drugs, differences among them were noted with respect to the sensitivity of each tumor cell type.

Tumor growth delay after treatment. The growth delay achieved using UFT and UFT/LV was assessed in the Co-3 xenograft model. After 14 days of continuous oral administration of LV at $10 \mathrm{mg} / \mathrm{kg} / \mathrm{day}$, UFT at $20 \mathrm{mg} / \mathrm{kg} /$ day or UFT/ $\mathrm{LV}$ at $20 / 10 \mathrm{mg} / \mathrm{kg} / \mathrm{day}$, the tumor diameters were determined two or three times a week until day 29 (the final day of assessment), and the duration until RTV reached 10 was calculated for each group. The durations achieved in the control, LV, UFT and UFT/LV groups were 8.68, 8.75, 13.81 and 17.25 days, respectively. The period of growth delay was prolonged by 5.14 days and 8.57 days in the UFT and UFT/LV groups, respectively, indicating that concomitant LV delayed tumor growth in comparison with UFT monotherapy (Fig. 1).

TS expression and its relationship to antitumor sensitivity of 5-FU prodrugs. For further analysis of the antitumor effect of each drug, the TS activities of the 11 cell lines used in the drug efficacy study were determined in the tumor tissues of the control group. Since it has been reported that, in the case of capecitabine, the stage of activation by TP affects the expression of the antitumor effect (13), TP activity was also determined (Fig. 2). The correlations between the sensitivities of each xenograft to UFT and UFT/LV and intratumor TS activity were determined. The antitumor effects of UFT and UFT/LV exhibited significant negative correlations with TS activity, although the correlation observed with UFT ( $\mathrm{r}=-0.862)$ was stronger than that observed with UFT/LV ( $r=-0.713)$ (Fig. 3). The effects of UFT and UFT/LV thus depended on intratumor TS activity, although modulation of the effect was less pronounced with concomitant LV. On the other hand, the antitumor effect of capecitabine exhibited a significant positive correlation with $\log \mathrm{TP} / \mathrm{TS}$ activity ratio $(\mathrm{r}=0.705, \mathrm{p}=0.015)$. This finding indicated that both TP and TS activity in the tumor tissue determined the antitumor effect of capecitabine.

Ternary complex formation in tumor tissues after drug treatment. Following the administration of LV to Co-3 xenografts exhibiting high intratumor TS activity, the level of reduced folate increased in the tumor tissue (Fig. 4A). The TS ternary complex and free TS in tumor tissues following the administration of each drug were detected using Western blotting with anti-human TS polyclonal antibody. After concomitant administration of UFT and LV, the amount of ternary complex in the tumor tissue was increased compared with that observed following administration of UFT alone. Furthermore, a decrease in free TS was observed (Fig. 4B).

Correlation between the IR of UFT/LV to UFT and tumoral $T S$ activities. When the increase in the effect of UFT caused by the concomitant administration of LV was represented by the IR for UFT/LV to that for UFT alone, the IR was found to be significantly correlated with TS activity in the tumor tissue, indicating that concomitant LV was more effective against tumors with a high TS activity (Fig. 5).

\section{Discussion}

We demonstrated that UFT/LV concomitant therapy was more effective than UFT monotherapy against colorectal tumors with high TS enzyme activity.

As a first step, we used mice that were fed a low folate diet and implanted with 11 different colorectal cancer cell types in order to investigate the antitumor effects of UFT, UFT/LV and capecitabine employed in the chemotherapy of colorectal cancer, and their relationships to TS activity in tumors (Table I). Differences were noted in the fluoropyrimidine sensitivity of the different cell lines when using these drugs. When LV was concomitantly administered with UFT, the antitumor effect of UFT was significantly enhanced in 10/11 cell lines. When delay in growth of the Co-3 cell line was assessed, tumor growth was found to be delayed more by the combination UFT/LV than by UFT alone (Fig. 1). These findings confirmed that concomitant LV increases the antitumor effect of UFT, resulting in a marked antitumor effect (12).

TS is a key enzyme and plays an important role in de novo DNA synthesis and cell proliferation. Accordingly, it is an important target for fluoropyrimidine drugs, including 5-FU, in the treatment of colorectal cancer and other tumors. UFT is known to exert cytotoxic effects by acting on both RNA and DNA after its conversion to 5-FU and metabolism in vivo. The cytocidal effect of 5-FU mediated via the inhibition of 
A

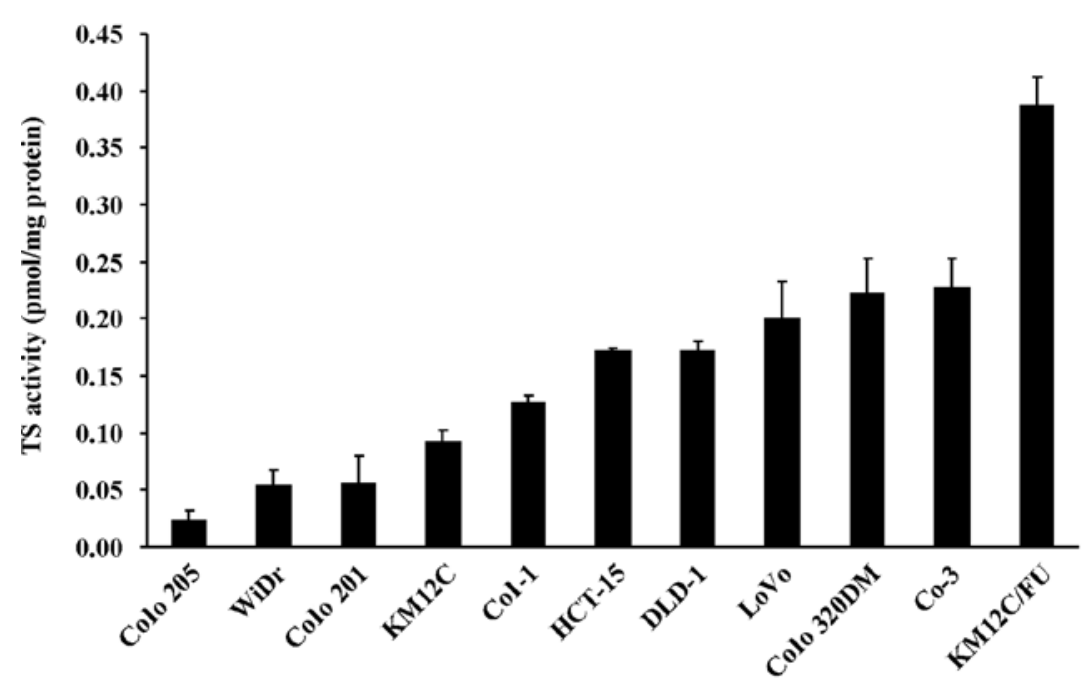

B

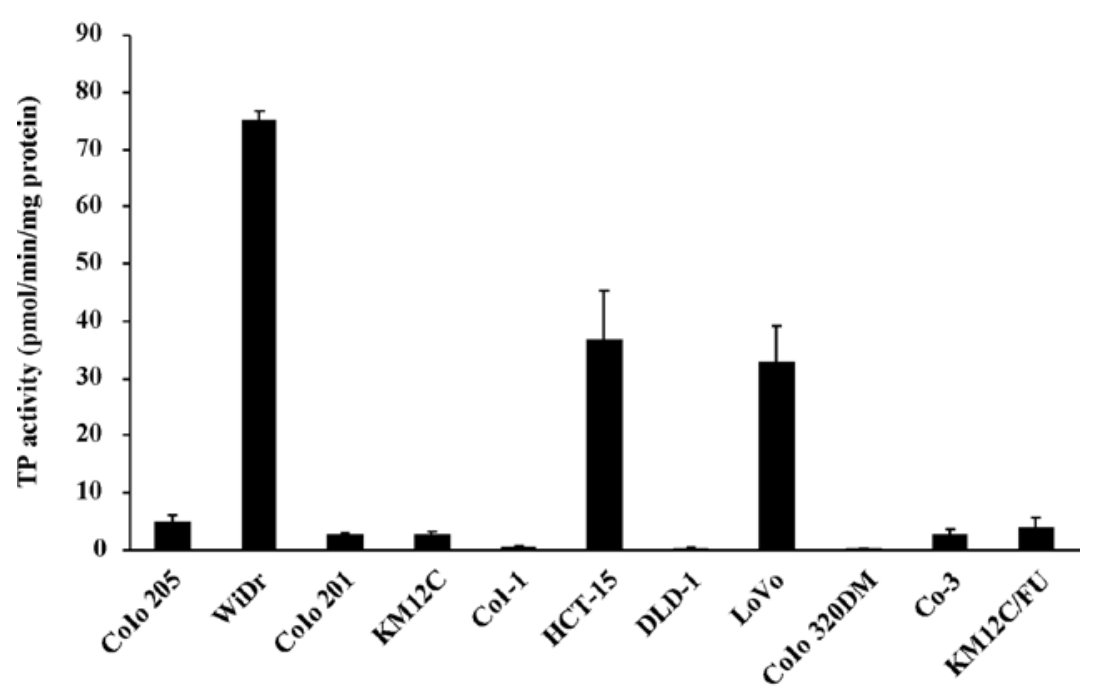

Figure 2. (A) TS and (B) TP enzyme activities in the tumor tissues of 11 human colon cancer xenografts were determined as previously described. The values are the mean \pm SD of three mice.

TS is considered particularly important in continuous treatment with concomitant LV or UFT monotherapy. Increase in TS activity as a result of TS gene transcription and enhanced mRNA translation has thus attracted attention as a mechanism of acquired drug resistance, as noted in numerous basic and clinical studies. Johnston et al reported that the $\mathrm{IC}_{50}$ value of 5-FU exhibited a significant correlation $\left(\mathrm{r}^{2}=0.94, \mathrm{p}=0.01\right)$ with the level of FdUMP binding in 5-FU-resistant colorectal cancer cells (NCI H630-R1 and H630-R10) and 5-FUinsensitive colorectal cancer cell lines (HCT116, SNU-C1 and SNU-C4) (19). The correlations between the $\mathrm{IC}_{50}$ values of 5-FU and 5-FU/LV and the catalytic activity of TS were also examined in 13 types of colorectal cancer cells by van Triest et al, who reported significant correlations with coefficients of $\mathrm{r}=0.68(\mathrm{p}=0.01)$ and $\mathrm{r}=0.62(\mathrm{p}=0.02)$, respectively (20). In our in vivo study, the coefficients of correlation between IR and TS binding activity for UFT and UFT/LV were $r=-0.862(p=0.0006)$ and $r=-0.713(p=0.014)$, respec- tively. However, the degree of correlation decreased and the effect of TS expression was less in the LV-concomitant group, indicating that concomitant therapy achieved comparatively more marked effects against tumors with high levels of TS expression (Fig. 3).

Numerous studies reported on the correlation between the level of TS protein or mRNA expression in metastatic lesions and tumor responses to them (21-31). Aschele et al (22) and Cascinu et al (23) classified TS expression in the metastatic region of tumors as low or high expression by immunohistochemistry (IHC), and examined the ratios of complete (CR) and partial response (PR) with 5-FU-based chemotherapy as a first-line treatment.

On the other hand, another study examined TS expression in tumor tissues (IHC) after curative resection and survival with regard to the amount of TS expression in the primary lesion and prognosis. The overall survival of TS-negative colon cancer patients was found to be significantly longer. 
A

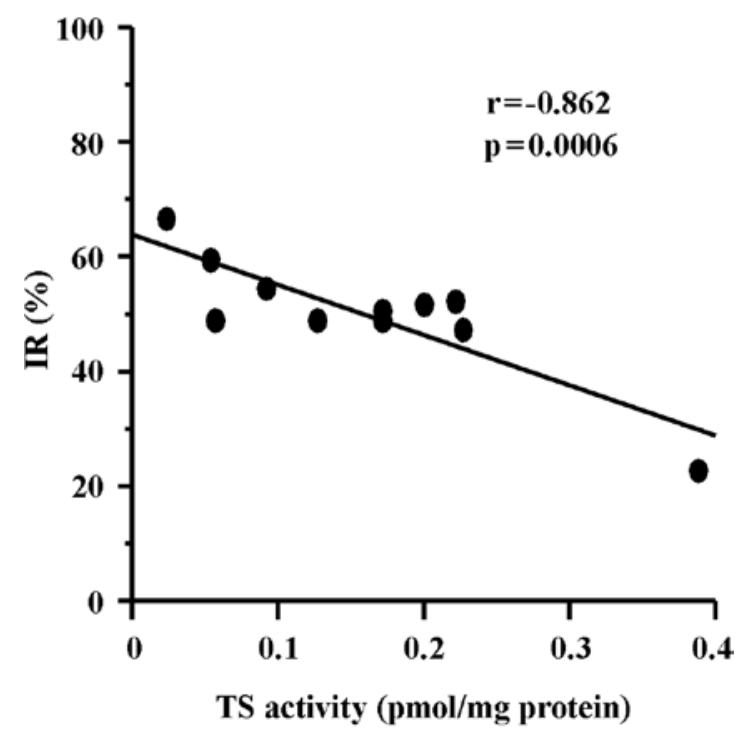

B

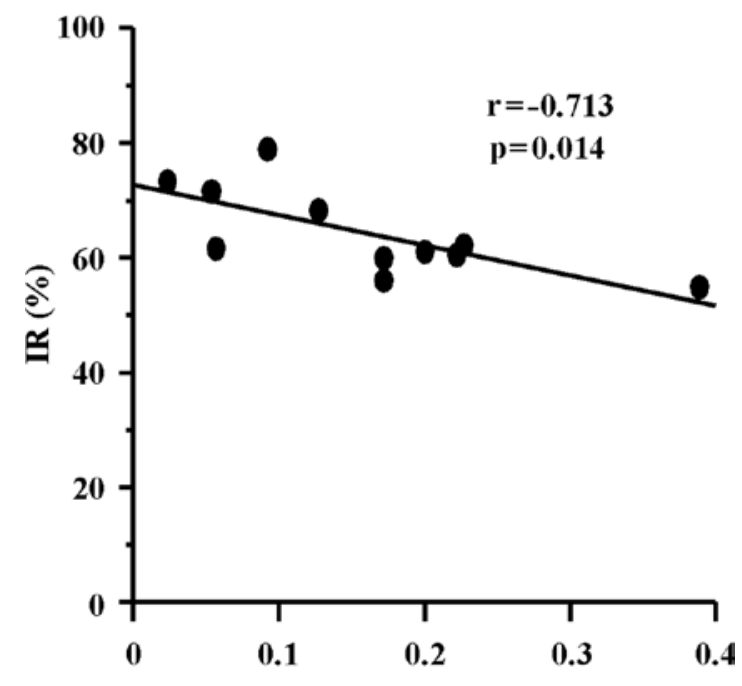

TS binding activity (pmol/mg protein)

Figure 3. Correlation between the in vivo susceptibilities of human cancer xenografts with (A) UFT or (B) UFT/LV and their TS activities. TS binding activity (pmol/mg protein) is plotted against the IR (\%) of (A) UFT ( $\mathrm{r}=-0.862$, $\mathrm{p}=0.0006)$ and $(\mathrm{B}) \mathrm{UFT} / \mathrm{LV}(\mathrm{r}=-0.713, \mathrm{p}=0.014)$.

Furthermore, the difference in survival of TS-negative colon cancer patients receiving or not receiving chemotherapy was negligible in the case of adjuvant therapy based on 5-FU, whereas the survival of TS-positive colon cancer patients was significantly longer if chemotherapy was performed (32). In a study that examined the level of gene expression in primary lesions, a significant correlation was observed between the decrease in metastatic lesion size and prolongation of survival when the level of TS mRNA expression in tumors was below the cut-off value categorized as either responding or not responding to a regimen of UFT and LV, even in primary
A

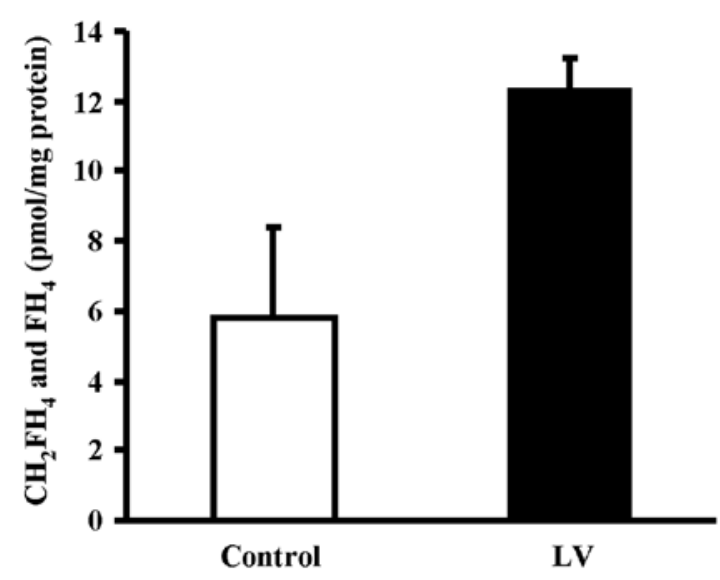

B

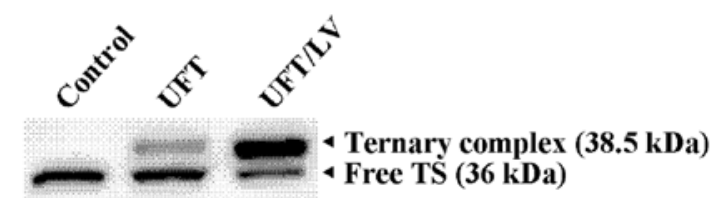

Figure 4. (A) Tissue levels of the reduced folate after treatment with LV. Intratumoral reduced folate levels after LV administration were determined at $24 \mathrm{~h}$ after a single administration of vehicle alone (white column) or $\mathrm{LV}$ at $10 \mathrm{mg} / \mathrm{kg}$ (black column). Values are the mean $\pm \mathrm{SD}$ of three mice. (B) Formation of the ternary complex after treatment with UFT and UFT/LV. Folate-depleted mice bearing Co-3 tumors were used for this experiment. Free TS protein and ternary complexes were detected using Western blotting at $24 \mathrm{~h}$ after a single administration of vehicle alone, or UFT $(20 \mathrm{mg} / \mathrm{kg})$ alone or in combination with LV (10 mg/kg).

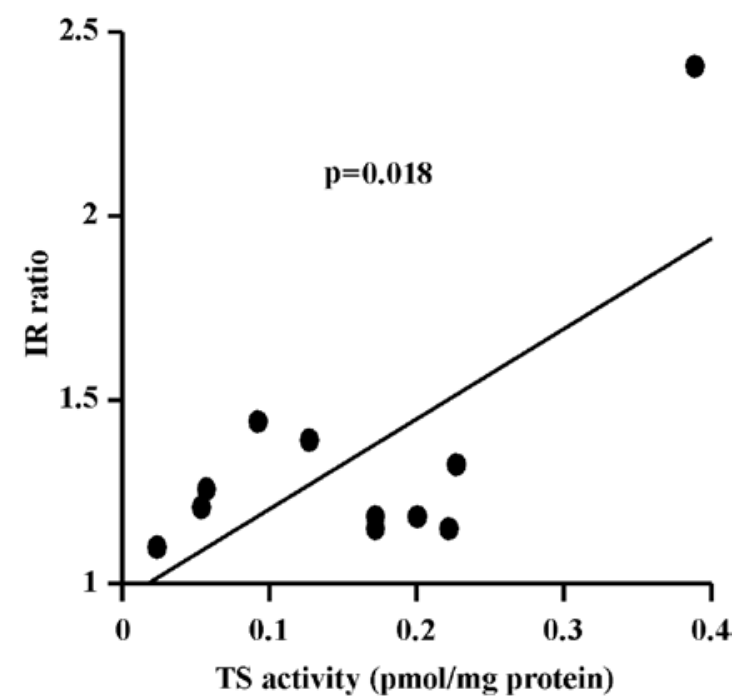

Figure 5. Correlation between the IR of UFT/LV to UFT and tumoral TS activities. TS binding activity (pmol/mg protein) is plotted against the IR of UFT/LV to UFT ( $\mathrm{r}=0.695, \mathrm{p}=0.018)$.

tumors (33). As noted above, TS expression in the tumor tissue strongly modulates not only advanced cancer but also the effects of adjuvant therapy based on 5-FU. A high TS expression was shown to be a cause of the lower sensitivity to fluoropyrimidine drugs in clinical practice. 
Using the same experimental system, we also examined the relationship between the antitumor effect of capecitabine employed in the chemotherapy of colorectal cancer involving agents such as UFT and UFT/LV and intratumor TS activity. Ishikawa et al previously analyzed the TP and DPD activities in tumors, and reported that the intratumor TP/DPD activity ratio showed a positive correlation with the antitumor effect of capecitabine in a xenograft model (13). Our findings showed a strong correlation between the antitumor effect of capecitabine and TP/TS activity ratio, indicating that this ratio determines the antitumor effect of capecitabine. In addition to TP activity, TS activity in tumor tissues also determines the antitumor effect of this agent.

The present study examined the mechanism of the effects of concomitant LV administration with UFT using Co-3 xenografts with high expression levels of TS. When LV was administered, the level of reduced folate in Co-3 tumors markedly increased (Fig. 4A), and, compared with UFT alone, this increase appeared to promote intratumor TS ternary complex formation in combination with UFT/LV (9). It appears that this promotion of ternary complex formation by LV subsequently decreased the level of free TS in the tumor and increased sensitivity to fluoropyrimidine drugs (Fig. 4B). Unlike approaches involving a decrease in the TS expression itself by use of other concomitant drugs, including gefitinib and HDACI, the concomitant administration of LV is likely to be effective not only against the high expression of TS induced by 5 -FU administration but also against tumors with a high TS expression due to factors such as gene amplification (19), as well as in colorectal cancer patients exhibiting a decreased rate of TS inhibition attributable to a decrease in the tumor levels of $5,10-\mathrm{CH}_{2}-\mathrm{FH}_{4}(8)$.

Concomitant use of a drug to reduce TS expression has been reported as a method of treatment for tumors with high intratumor TS activity. Lee et al (34) showed that exposure of a 5-FU-resistant gastric cancer cell line, SNU-484, to a low concentration of the HDAC inhibitor trichostatin A did not inhibit cell growth if it was applied alone, and demonstrated a decrease in TS protein expression. The authors also demonstrated that the cell growth inhibitory effect was significantly increased by sequential exposure to 5-FU in comparison with the single exposure to 5-FU. Regarding the regulation of TS cytotoxic drugs, Wada et al (35) and Takiuchi et al (36) have also demonstrated that docetaxel (TXT) and irinotecan (CPT-11), down-regulate TS activity in gastric cancer cells with high expression levels of TS, thereby augmenting the antitumor activity in combination with the 5-FU prodrug S-1 (combined form of tegafur, gimeracil and oteracil). The combination of S-1 with CPT-11 in particular was proven to be clinically effective in gastric cancer patients with high TS levels, whereas S-1 alone did not show a similar efficacy in such patients (36). These findings indicate that it is possible to modulate the effects of fluoropyrimidine drugs by decreasing TS, a target enzyme of 5-FU.

In conclusion, the findings of this study suggest that UFT/LV concomitant therapy can achieve strong antitumor effects against various types of tumors with a high TS expression and low 5-FU sensitivity by decreasing free TS levels through the promotion of ternary complex formation in tumor tissues. UFT/LV concomitant therapy is thus anticipated to be extremely useful, particularly in colorectal cancer patients with high TS activity.

\section{References}

1. Kuebler JP, Wieand HS, O'Connell MJ, et al: Oxaliplatin combined with weekly bolus fluorouracil and leucovorin as surgical adjuvant chemotherapy for stage II and III colon cancer: results from NSABP C-07. J Clin Oncol 25: 2198-2204, 2007.

2. De Gramont A, Figer A, Seymour M, et al: Leucovorin and fluorouracil with or without oxaliplatin as first-line treatment in advanced colorectal cancer. J Clin Oncol 18: 2938-2947, 2000.

3. Tournigand C, Andre T, Achille E, et al: FOLFIRI followed by FOLFOX6 or the reverse sequence in advanced colorectal cancer: a randomized GERCOR study. J Clin Oncol 22: 229-237, 2004.

4. Maindrault-Goebel F, De Gramont A, Louvet C, et al: High-dose intensity oxaliplatin added to the simplified bimonthly leucovorin and 5-fluorouracil regimen as second-line therapy for metastatic colorectal cancer (FOLFOX 7). Eur J Cancer 37: 1000-1005, 2001.

5. Shirao K, Hoff PM, Ohtsu A, et al: Comparison of the efficacy, toxicity, and pharmacokinetics of a uracil/tegafur (UFT) plus oral leucovorin (LV) regimen between Japanese and American patients with advanced colorectal cancer: joint United States and Japan study of UFT/LV. J Clin Oncol 22: 3466-3474, 2004.

6. Lembersky BC, Wieand HS, Petrelli NJ, et al: Oral uracil and tegafur plus leucovorin compared with intravenous fluorouracil and leucovorin in stage II and III carcinoma of the colon: results from National Surgical Adjuvant Breast and Bowel Project Protocol C-06. J Clin Oncol 24: 2059-2064, 2006.

7. Cassidy J, Tabernero J, Twelves C, et al: XELOX (capecitabine plus oxaliplatin): active first-line therapy for patients with metastatic colorectal cancer. J Clin Oncol 22: 2084-2091, 2004.

8. Spears CP, Gustavsson BG, Berne M, Frosing R, Bernstein L and Hayes AA: Mechanisms of innate resistance to thymidylate synthase inhibition after 5-fluorouracil. Cancer Res 48: 5894-5900, 1988.

9. Houghton JA, Maroda SJ Jr, Phillips JO and Houghton PJ: Biochemical determinants of responsiveness to 5-fluorouracil and its derivatives in xenografts of human colorectal adenocarcinomas in mice. Cancer Res 41: 144-149, 1981.

10. Van der Wilt CL, Backus HH, Smid K, et al: Modulation of both endogenous folates and thymidine enhance the therapeutic efficacy of thymidylate synthase inhibitors. Cancer Res 61: 3675-3681, 2001.

11. Raghunathan K, Schmitz JC and Priest DG: Impact of schedule on leucovorin potentiation of fluorouracil antitumor activity in dietary folic acid deplete mice. Biochem Pharmacol 53: 1197-1202, 1997.

12. Okabe H, Toko T, Saito H, et al: Augmentation of the chemotherapeutic effectiveness of UFT, a combination of tegafur [1-(2-tetrahydrofuryl)-5-fluorouracil] with uracil, by oral l-leucovorin. Anticancer Res 17: 157-164, 1997.

13. Ishikawa T, Sekiguchi F, Fukase Y, Sawada N and Ishitsuka H: Positive correlation between the efficacy of capecitabine and doxifluridine and the ratio of thymidine phosphorylase to dihydropyrimidine dehydrogenase activities in tumors in human cancer xenografts. Cancer Res 58: 685-690, 1998.

14. Bradford MM: A rapid and sensitive method for the quantitation of microgram quantities of protein utilizing the principle of protein-dye binding. Anal Biochem 72: 248-254, 1976.

15. Spears CP, Shahinian AH, Moran RG, Heidelberger $\mathrm{C}$ and Corbett TH: In vivo kinetics of thymidylate synthetase inhibition of 5-fluorouracil-sensitive and -resistant murine colon adenocarcinomas. Cancer Res 42: 450-456, 1982.

16. Priest DG, Schmitz JC, Bunni MA and Stuart RK: Pharmacokinetics of leucovorin metabolites in human plasma as a function of dose administered orally and intravenously. J Natl Cancer Inst 83: 1806-1812, 1991.

17. Burnette WN: 'Western blotting': electrophoretic transfer of proteins from sodium dodecyl sulfate-polyacrylamide gels to unmodified nitrocellulose and radiographic detection with antibody and radioiodinated protein A. Anal Biochem 112: 195-203, 1981. 
18. Drake JC, Allegra CJ and Johnston PG: Immunological quantitation of thymidylate synthase-FdUMP-5,10-methylenetetrahydrofolate ternary complex with the monoclonal antibody TS 106. Anticancer Drugs 4: 431-435, 1993.

19. Johnston PG, Drake JC, Trepel J and Allegra CJ: Immunological quantitation of thymidylate synthase using the monoclonal antibody TS 106 in 5-fluorouracil-sensitive and -resistant human cancer cell lines. Cancer Res 52: 4306-4312, 1992.

20. Van Triest B, Pinedo HM, van Hensbergen Y, et al: Thymidylate synthase level as the main predictive parameter for sensitivity to 5-fluorouracil, but not for folate-based thymidylate synthase inhibitors, in 13 nonselected colon cancer cell lines. Clin Cancer Res 5: 643-654, 1999.

21. Salonga D, Danenberg KD, Johnson M, et al: Colorectal tumors responding to 5-fluorouracil have low gene expression levels of dihydropyrimidine dehydrogenase, thymidylate synthase, and thymidine phosphorylase. Clin Cancer Res 6: 1322-1327, 2000.

22. Aschele C, Debernardis D, Casazza S, et al: Immunohistochemical quantitation of thymidylate synthase expression in colorectal cancer metastases predicts for clinical outcome to fluorouracilbased chemotherapy. J Clin Oncol 17: 1760-1770, 1999.

23. Cascinu S, Aschele C, Barni S, et al: Thymidylate synthase protein expression in advanced colon cancer: correlation with the site of metastasis and the clinical response to leucovorinmodulated bolus 5-fluorouracil. Clin Cancer Res 5: 1996-1999, 1999.

24. Davies MM, Johnston PG, Kaur S and Allen-Mersh TG: Colorectal liver metastasis thymidylate synthase staining correlates with response to hepatic arterial floxuridine. Clin Cancer Res 5: 325-328, 1999.

25. Corsi DC, Ciaparrone M, Zannoni G, et al: Predictive value of thymidylate synthase expression in resected metastases of colorectal cancer. Eur J Cancer 38: 527-534, 2002.

26. Gonen M, Hummer A, Zervoudakis A, et al: Thymidylate synthase expression in hepatic tumors is a predictor of survival and progression in patients with resectable metastatic colorectal cancer. J Clin Oncol 21: 406-412, 2003.

27. Leichman CG, Lenz HJ, Leichman L, et al: Quantitation of intratumoral thymidylate synthase expression predicts for disseminated colorectal cancer response and resistance to protracted-infusion fluorouracil and weekly leucovorin. J Clin Oncol 15: 3223-3229, 1997.
28. Shirota Y, Stoehlmacher J, Brabender J, et al: ERCC1 and thymidylate synthase mRNA levels predict survival for colorectal cancer patients receiving combination oxaliplatin and fluorouracil chemotherapy. J Clin Oncol 19: 4298-4304, 2001.

29. Etienne MC, Chazal M, Laurent-Puig P, et al: Prognostic value of tumoral thymidylate synthase and p53 in metastatic colorectal cancer patients receiving fluorouracil-based chemotherapy: phenotypic and genotypic analyses. J Clin Oncol 20: 2832-2843, 2002.

30. Johnston PG, Lenz HJ, Leichman CG, et al: Thymidylate synthase gene and protein expression correlate and are associated with response to 5-fluorouracil in human colorectal and gastric tumors. Cancer Res 55: 1407-1412, 1995.

31. Kornmann M, Link KH, Lenz HJ, et al: Thymidylate synthase is a predictor for response and resistance in hepatic artery infusion chemotherapy. Cancer Lett 118: 29-35, 1997.

32. Takenoue $\mathrm{T}$, Nagawa $\mathrm{H}$, Matsuda $\mathrm{K}$, et al: Relation between thymidylate synthase expression and survival in colon carcinoma, and determination of appropriate application of 5-fluorouracil by immunohistochemical method. Ann Surg Oncol 7: 193-198, 2000.

33. Ichikawa W, Uetake H, Shirota Y, et al: Combination of dihydropyrimidine dehydrogenase and thymidylate synthase gene expressions in primary tumors as predictive parameters for the efficacy of fluoropyrimidine-based chemotherapy for metastatic colorectal cancer. Clin Cancer Res 9: 786-791, 2003.

34. Lee JH, Park JH, Jung Y, et al: Histone deacetylase inhibitor enhances 5-fluorouracil cytotoxicity by down-regulating thymidylate synthase in human cancer cells. Mol Cancer Ther 5: 3085-3095, 2006.

35. Wada Y, Yoshida K, Suzuki T, et al: Synergistic effects of docetaxel and S-1 by modulating the expression of metabolic enzymes of 5-fluorouracil in human gastric cancer cell lines. Int J Cancer 119: 783-791, 2006.

36. Takiuchi H, Kawabe S, Gotoh M and Katsu K: Thymidylate synthase gene expression in primary tumors predicts activity of s-1-based chemotherapy for advanced gastric cancer. Gastrointest Cancer Res 1: 171-176, 2007. 